\title{
The Impact of Supply Chain Management Practices on Performance of Small and Medium Enterprises in Developing Countries: A Case of Agro-Dealers in Zambia
}

\author{
Mubanga Josephine Chileshe ${ }^{1}$, Jackson Phiri² \\ ${ }^{1}$ Graduate School of Business, University of Zambia, Lusaka, Zambia \\ ${ }^{2}$ Department of Computer Sciences, School of Natural Sciences, University of Zambia, Lusaka, Zambia \\ Email: mchileshej@gmail.com, Jackson.phiri@cs.unza.zm
}

How to cite this paper: Chileshe, M. J., \& Phiri, J. (2022). The Impact of Supply Chain Management Practices on Performance of Small and Medium Enterprises in Developing Countries: A Case of Agro-Dealers in Zambia. Open Journal of Business and Management, 10, 591-605.

https://doi.org/10.4236/ojbm.2022.102033

Received: November 22, 2021

Accepted: February 14, 2022

Published: February 17, 2022

Copyright $\odot 2022$ by author(s) and Scientific Research Publishing Inc. This work is licensed under the Creative Commons Attribution International License (CC BY 4.0).

http://creativecommons.org/licenses/by/4.0/

\begin{abstract}
The Agro-sector in Zambia has evolved over the years contributing about twenty percent (20\%) of the gross domestic product (GDP). Today organizations encounter with environment of global competition and for prosperity in this environment, we need radical changes and creativity in work. Supply chain management (SCM) is a thunderstruck organization with higher and lower relationship that is involved in process and activities and like presentation product and services to final customers to create value. It is important in organization. In this research the aim was checking the influence that the adoption of supply chain management practices has in business performance through competitive priorities. The concept of SCM has received increasing attention from academicians, consultants, and business managers alike (Tan, Lyman, \& Wisner, 2002). Various theories have offered insights on specific aspects or perspectives of SCM, such as industrial organization and associated transaction cost analysis, resource-based and resource-dependency theory, competitive strategy, and social-political perspective (Stern \& Reve, 1980). However, despite the increased attention paid to SCM, the literature has not been able to offer much by way of guidance to help the practice of SCM. This has been attributed to the interdisciplinary origin of SCM, the conceptual confusion, and the evolutionary nature of SCM concept. Much of the current theoretical/empirical research in SCM focuses on only the upstream or downstream side of the supply chain, or certain aspects/perspectives of SCM. This identified a research gap to be filled by looking at both the downstream and upstream sides of the supply chain and linking such activities to both competitive advantage and organizational performance. The target population was Small and Medium Agro-dealers in Lusaka with a calculated sample
\end{abstract}


size of 151. Regression Analysis was used to answer the hypothesis. Research findings indicate that application of supply chain management influences performance according to competitive priorities.

\section{Keywords}

Supply Chain Management, Performance, Competitive Advantage

\section{Introduction}

The idea of supply chain management is to evaluate the processes of planning implementation and controlling of material, of finished goods all the way to the end-user; the interconnected activities of supply chain begin with a customer order, and are complete when the goods are in the hands of the customers. The concept of supply chain management (SCM) has received increasing attention from academicians, consultants and business managers alike (Wong, Arlbjorn, \& Johansen, 2005). SCM has been defined to explicitly recognize the strategic nature of coordination between trading parties and to explain the dual purpose of SCM; to improve performance of an individual organization and to improve performance of the whole chain.

SCM practices are defined as the set of activities undertaken by an organization to promote effective management of its supply chain. The practices of SCM are proposed to be a multi-dimensional concept, including the downstream and upstream sides of the supply chain. Operational measures for the constructs are developed and tested empirically, using data collected from respondents to a survey questionnaire. Structural equation modeling is used to test the hypothesized relationships. It is expected that the current research, by addressing SCM practices simultaneously from both upstream and downstream sides of a supply chain, will help researchers better understand the scope and the activities associated with SCM and allow researchers to test the antecedences and consequences of SCM practice. Further, by offering a validated instrument to measure SCM practices, and by providing empirical evidence of the impact of SCM practices on an organization's competitive advantage and its performance, it is expected that this research will offer useful guidance for measuring and implementing SCM practices in an organization and facilitate further research in this area.

The supply chain management practices (SCMP) are defined as the approaches applied in integration, managing and coordination of supply, demand and relationships in order to satisfy clients in an effective way as the set of activities undertaken by an organization to promote effective management of its supply chain (Li, Rao, Ragu-Nathan, \& Ragu-Nathan, 2002), as tangible technologies that have a relevant role in the collaboration of focal firm with its supplier and clients.

The early attempts of empirical research in SCM have been limited at devel- 
oping instruments capable of measuring SCM practices. Most recently, some researchers have focused their research efforts on exploring the relationship between practices of SCM and organizational performance. They have used financial and market criteria to operationalize organizational performance (return on investment, market share, profit margin on sales, the growth of return on investment, the growth of sales and the growth of market share). Also, they investigated the relationship among SCM practices, operational performance and SCM-related organizational performance. These studies and others have produced various results due to operationalizing the performance of the organization subjectively and objectively. Supply-chain driven organizational performance falls into three categories. First, resource performance reflects value addition in the form of achieving efficiency. Second, output performance reflects value addition as the firm's ability to provide high levels of customer service. Last, flexibility performance reflects value addition as the firm's ability to respond. As competition in the 1990s intensified and markets became global, so did the challenges associated with getting a product and service to the right place at the right time at the lowest cost. Organizations began to realize that it is not enough to improve efficiencies within an organization, but their whole supply chain has to be made competitive. The understanding and practicing of supply chain management (SCM) has become an essential prerequisite for staying competitive in the global race and for enhancing profitably. It is for these reasons that the researcher felt the need to carry out this research especially in the Small businesses were supply chain management concepts have been neglected and less attention has been given. Therefore the findings of this research will help small scale businesses to learn to embrace SCM practices in their day to day operations in order to improve their business performance and keep in touch with their suppliers. This article will also add on the board of knowledge especially that it is a locally done work other than relying on works which have been done in developed countries in which the business conditions and operations are totally different to that of Zambia. This paper is divided into five main sections. The first section has provided an introduction to the paper. The second section presents and discusses the literature review regarding supply chain management, its impact on business performance and the challenges associated with supply chain management and performance. The third section discusses research methodology and the fourth section provides the research findings to the topic by the linear regression model. The fifth section summarizes the discussion analysed from the findings in chapter four and concludes the paper.

\section{Literature Review}

SCM practices have been defined as a set of activities undertaken in an organization to promote effective management of its supply chain. Donlon (1996) describes the latest evolution of SCM practices, which include supplier partnership, 
outsourcing, cycle time compression, continuous process flow, and information technology sharing. Tan et al. use purchasing, quality, and customer relations to represent SCM practices, in their empirical study. Tan et al. identify six aspects of SCM practice through factor analysis: supply chain integration, information sharing, supply chain characteristics, customer service management, geographical proximity and JIT capability. Thus the literature portrays SCM practices from a variety of different perspectives with a common goal of ultimately improving organizational performance. In reviewing and consolidating the literature, five distinctive dimensions, including strategic supplier partnership, customer relationship, level of information sharing, quality of information sharing and postponement, are selected for measuring SCM practice. The five constructs cover upstream (strategic supplier partnership) and downstream (customer relationship) sides of a supply chain, information flow across a supply chain (level of information sharing and quality of information sharing), and internal supply chain process (postponement). It should be pointed out that even though the above dimensions capture the major aspects of SCM practice, they cannot be considered complete. Other factors, such as geographical proximity, cross-functional teams, logistics integration, agreed vision and goals, and agreed supply chain leadership are also identified in the literature. Though these factors are of great interest, they are not included due to the concerns regarding the length of the survey and the parsimony of measurement instruments.

Strategic supplier partnership-The long-term relationship between the organization and its suppliers. It is designed to leverage the strategic and operational capabilities of individual participating organizations to help them achieve significant ongoing benefits (Stuart, 1997; Balsmeier \& Voisin, 1996). A strategic partnership emphasizes direct, long-term association and encourages mutual planning and problem solving efforts (Gunasekaran, Patel, \& Tirtiroglu, 2001). Such strategic partnerships are entered into to promote shared benefits among the parties and ongoing participation in one or more key strategic areas such as technology, products, and markets. Strategic partnerships with suppliers enable organizations to work more effectively with a few important suppliers who are willing to share responsibility for the success of the products. Suppliers participating early in the product-design process can offer more cost effective design choices, help select the best components and technologies, and help in design assessment (Yoshino \& Rangan, 1995).

Customer relationship-The entire array of practices that are employed for the purpose of managing customer complaints, building long-term relationships with customers, and improving customer satisfaction. Someone considers customer relationship management as an important component of SCM practices, as pointed out by them, committed relationships are the most sustainable advantage because of their inherent barriers to competition. The growth of mass customization and personalized service is leading to an era in which relationship management with customers is becoming crucial for corporate survival. Good 
relationships with supply chain members, including customers, are needed for successful implementation of SCM programs. Close customer relationship allows an organization to differentiate its product from competitors, sustain customer loyalty, and dramatically extend the value it provides to its customers (Magretta, 1998).

Level of information sharing-The extent to which critical and proprietary information is communicated to one's supply chain partner. Many researchers have suggested that the key to the seamless supply chain is making available undistorted and up-to-date marketing data at every node within the supply chain (Childhouse \& Towill, 2003; Balsmeier \& Voisin, 1996). By taking the data available and sharing it with other parties within the supply chain, information can be used as a source of competitive advantage considers sharing of information as one of five building blocks that characterize a solid supply chain relationship. Supply chain partners who exchange information regularly are able to work as a single entity. Together, they can understand the needs of the end customer better and hence can respond to market change quicker. Moreover, someone considers the effective use of relevant and timely information by all functional elements within the supply chain as a key competitive and distinguishing factor. The empirical findings of they reveal that simplified material flow, including streamlining and making highly visible all information flow throughout the chain, is the key to an integrated and effective supply chain, including such aspects as the accuracy, timeliness, adequacy, and credibility of information exchanged (McGinnis \& Vallopra, 1999).

Quality of information sharing-Refers to the accuracy, timeliness, adequacy, and credibility of information exchanged (Chizzo, 1998).

The concept of SCM has received increasing attention from academicians, consultants, and business managers alike (Tan, Lyman, \& Wisner, 2002). Many organizations have begun to recognize that SCM is the key to building sustainable competitive edge for their products and/or services in an increasingly crowded marketplace (McGinnis \& Vallopra, 1999). The concept of SCM has been considered from different points of view in different bodies of literature such as purchasing and supply management, logistics and transportation, operations management, marketing, organizational theory, and management information systems. Various theories have offered insights on specific aspects or perspectives of SCM, such as industrial organization and associated transaction cost analysis, resource-based and resource-dependency theory, competitive strategy, and social-political perspective (Li, Rao, Ragu-Nathan, \& Ragu-Nathan, 2002). However, despite the increased attention paid to SCM, the literature has not been able to offer much by way of guidance to help the practice of SCM. This has been attributed to the interdisciplinary origin of SCM, the conceptual confusion, and the evolutionary nature of SCM concept. Much of the current theoretical/empirical research in SCM focuses on only the upstream or downstream side of the supply chain, or certain aspects/perspectives of SCM. Topics such as 
supplier selection, supplier involvement, and manufacturing performance, the influence of supplier alliances on the organization, success factors in strategic supplier alliances, supplier management orientation and supplier/buyer performance, the role of relationships with suppliers in improving supplier responsiveness, and the antecedence and consequences of buyer-supplier relationship have been researched on the supplier side. Studies such as those by Clark \& Lee (2000), focus on the downstream linkages between manufacturers and retailers. A few recent studies have considered both the upstream and downstream sides of the supply chain simultaneously. Tan, Lyman, \& Wisner (2002) explore the relationships between supplier management practices, customer relations practices and organizational performance; Frohlich and Westbrook investigate the effects of supplier-customer integration on organizational performance. Taken together, these studies are representative of efforts to address various diverse but interesting aspects of SCM practices. However, the absence of an integrated framework, incorporating all the activities both upstream and downstream sides of the supply chain and linking such activities to both competitive advantage and organizational performance, detracts from usefulness of the implementation of previous results on SCM. Therefore the purpose of this study is therefore to empirically test a framework identifying the relationships among SCM practices, competitive advantage and organizational performance.

\section{Conceptual Framework}

The figure below shows the conceptual framework that has been adopted for this research. This framework proposes that supply chain management practices will have an impact on performance of an organization both directly and indirectly through competitive advantage. The existing literature helps to conceptualize the existing relationship between supply chain management practices, competitive advantage and organization performance.

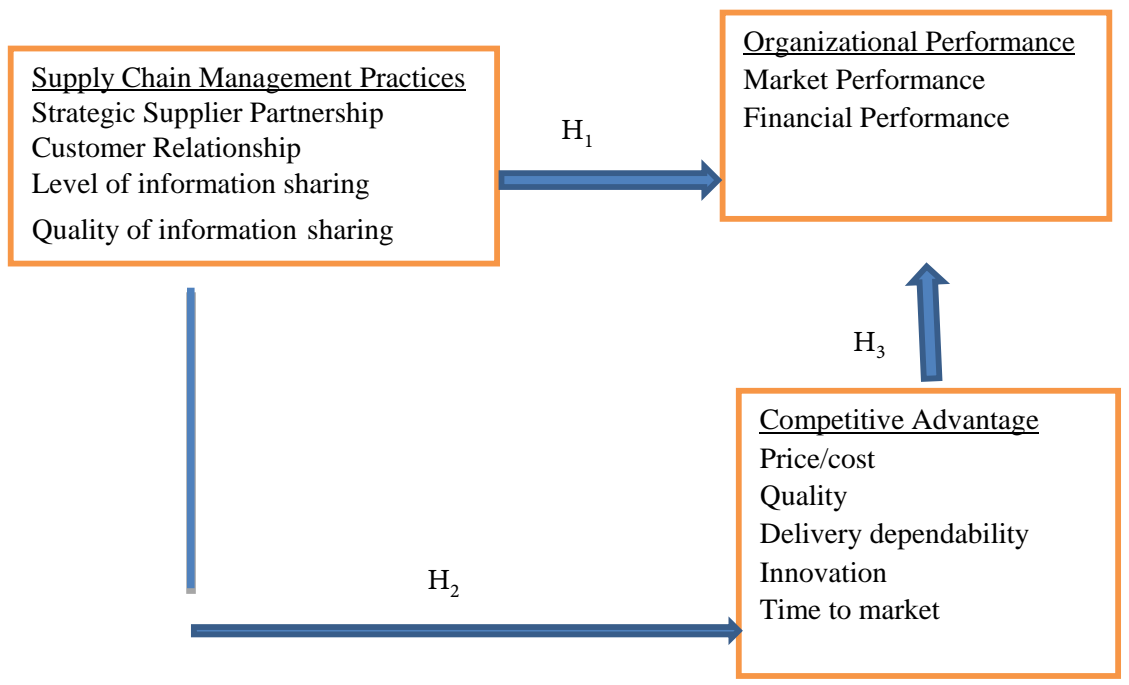


The SCM framework for this study proposes that SCM practices have a direct impact on the performance of an organization's practices, when implemented are expected to increase organization's market share, return on investment and overall competitive advantage.

Based on the study the following hypotheses were formulated;

$\mathrm{H}_{1}$ : Organizations with high levels of SCM practices have high levels of organization performance;

$\mathrm{H}_{2}$ : Organizations with high levels of SCM practices have high levels of competitive advantage;

$\mathrm{H}_{3}$ : The higher the level of competitive advantage the higher the organization performance.

\section{Research Methodology}

This study employed quantitative survey design. The researcher used quantitative research in order to respond to relations questions between variables. To collect data for this study, the researcher used questionnaires. Information collected was analyzed using SPSS and regression analysis to establish the relationship and impact between variables. The target population for this was small and medium enterprises in the Agro-sector that are registered with PACRA. The Yamane formula was used to calculate the sample size of 151 that was used to distribute the questionnaires $n=N /\left(1+N(e)^{2}\right)$.

Registered SMEs in Agro-dealing as of $2020=243$ (PACRA data)

Margin of precision $(e)=0.05$

$$
\begin{aligned}
n & =\frac{N}{\left[1+N(e)^{2}\right]} \\
& =\frac{243}{\left[1+243(0.05)^{2}\right]} \\
& =151
\end{aligned}
$$

\section{Data Collection and Analysis}

The population of this study includes the Small and Medium agro-dealers in Lusaka district listed and registered with PACRA. A total of 243 Agro-dealers are registered with PACRA by 2020. Using the Yamane formula, the sample size was calculated to be 151 . To get this desired sample size, 171 questionnaires were distributed personally and out of these 151 were returned and fully completed indicating the response rate above eighty (80\%).

The means and standard deviation for each category were calculated using SPSS.

From the literature review, the most important dimensions that capture SCM practices construct have been chosen, which are: strategic supply partnership, quality of information sharing, level of information sharing and customer relationship management. Therefore the researcher employed multiple linear re- 
gression to determine which variables were significant using the $95 \%$ significance level ( $\left.p^{\star} 0.05\right)$. The performance of the SMEs was the dependent variable for this study and can be defined as the set of criterion used to measure the extent to which supply chain is accomplishing its objectives. From the literature review, the most critical measure of performance was identified to include: competitive price offering, dependable delivery, return to investment as well as growth in return to investment and growth in sales volume. These variables were then regressed with supply chain performance to identify the significant variables.

To answer the research questions to determine if the significant variables have an impact on the supply chain performance, each of the significant variables was regressed with supply chain performance using simple linear regression to find out their impact on the supply chain performance.

\section{Results and Discussion}

From the literature review, the most important dimensions that capture SCM practices construct have been chosen, which are: strategic supply partnership, quality of information sharing, level of information sharing and customer relationship management. Therefore, supply chain performance is the dependent variable for this study and can be defined as the set of criterion used to measure the extent to which supply chain is accomplishing its objectives. From the literature review, the most critical measure of supply chain performance was identified to include: competitive price offering, dependable delivery, return to investment as well as growth in return to investment and growth in sales volume. This paper theorises and develops five dimensions (strategic supplier partnership, level of information sharing, quality of information sharing, customer service management and postponement) into an SCM practices (SCMPs) construct and studies its causal relationship with the conceptualised constructs of supply chain performance (SCP) and Small-Medium Enterprises (SMEs) performance. The findings also explore the causal relationship between SCP and SMEs performance.

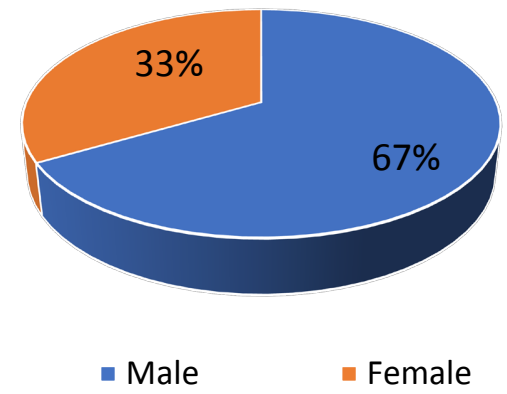

Figure 1. Gender of respondents.

Figure 1 shows the gender of the respondents. Sixty-seven percent of the respondents were male while thirty three percent were female. 


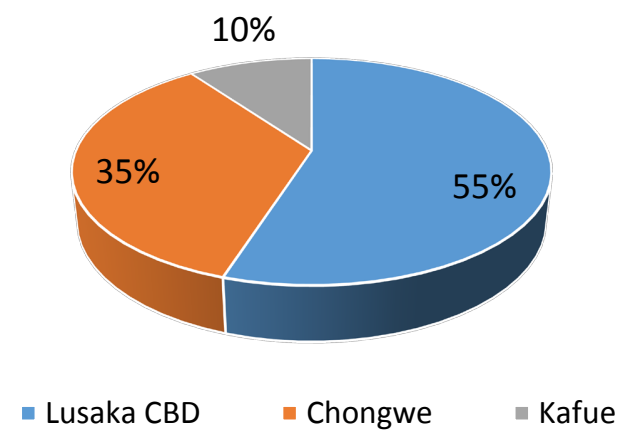

Figure 2. Location of respondents.

Figure 2 shows the location of the respondents. The respondents were mainly from Lusaka district (55\%), 35\% from Chongwe, and 10\% from Kafue and surrounding areas.

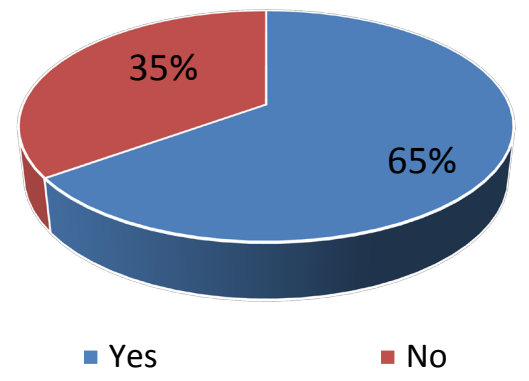

Figure 3. Knowledge about supply chain management.

Figure 3 shows the percentage of respondents who had knowledge about SCM. Sixty five percent showed some knowledge about SCM while thirty five percent did not.

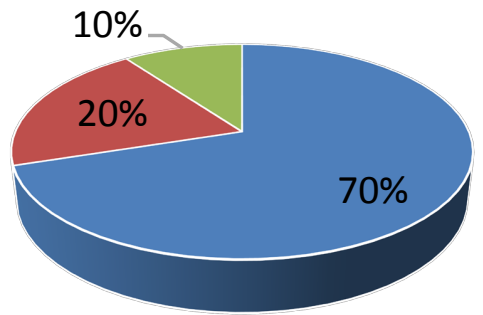

- Owner/top management " sales person " general employee

Figure 4. Position of the respondents in the business.

Figure 4 shows that seventy percent of the respondents were either business owners or in the top management of the business while twenty percent were sales personnel and $10 \%$ general business employees. This proves that the information collected was reliable as the most of the respondents were owners and or top business managers who are directly involved in procurements and selling of products. 
Table 1 is the linear regression output that was used to determine if there any relationship of SCM practices on performance. The $p$-value analysis, as shown above, shows that only Strategic Supplier Relationship (SSR), Level of information sharing and Quality of Information Sharing are significantly important in predicting the variability in Supply Chain Performance. While the $p$-value of customer relationship is 0.864 which renders it insignificant in the regression analysis.

Supply Chain Management has a significant and positive relationship on the supply chain performance of the SMEs. A one percent increase in the Strategic Supplier Relation will increase the supply chain performance by 0.308 according to the multiple regression above. A one percent increase in the level of information sharing between agro-dealers and their suppliers will increase the competitive advantage (supply chain performance) by 0.243 according to the multiple regression output above. Lastly a one percent increase in the quality of information sharing will increase the competitive advantage by 0.154 . Therefore these variables have a significant relationship with supply chain performance. $\mathrm{R}^{2}=$ 0.862 which means the volatility and variability in supply chain practices is explained by the four management practices that are being studied.

Table 2 shows the correlation of all SCMPs at a statistical significant difference of $p<0.05$ and the proportion of variance and the F-value was 234.717.

There was a 0.861 correlation between Supply Chain Management Practices and Competitive Advantage. This indicates that SCMPs is highly correlated with Competitive Advantage. The table also shows a 0.637 correlation between SCMPs and Business performance. This figure indicates a very high and positive correlation. Therefore an Increase in the SCMPs will increase competitive advantage in a business and this increased competitive advantage will consequently increase the Business Performance.

There was a 0.854 correlation between SME performance and Competitive advantage. This indicates a strong correlation between these two variables. Therefore an increase in competitive advantage will increase the performance of a business in either financial performance or market performance.

Table 1. Summary of coefficients (SPSS output).

\begin{tabular}{|c|c|c|c|c|c|c|c|}
\hline \multirow{2}{*}{ Model } & \multicolumn{2}{|c|}{$\begin{array}{l}\text { Unstandardized } \\
\text { Coefficients }\end{array}$} & \multirow{2}{*}{$\begin{array}{c}\begin{array}{c}\text { Standardized } \\
\text { Coefficients }\end{array} \\
\text { Beta }\end{array}$} & \multirow[t]{2}{*}{$\mathrm{t}$} & \multirow[t]{2}{*}{$p$-value } & \multicolumn{2}{|c|}{ 95\% Confidence Interval for B } \\
\hline & $\mathrm{B}$ & Std. Error & & & & Lower Bound & Upper Bound \\
\hline (Constant) & 3.429 & 0.696 & & 4.930 & $0.000^{\star *}$ & 2.054 & 4.804 \\
\hline Strategic Supplier Relationship (SSR) & 0.401 & 0.100 & 0.308 & 4.014 & $0.000^{* *}$ & 0.203 & 0.598 \\
\hline Customer Relationship & 0.013 & 0.079 & 0.013 & 0.171 & 0.864 & -1.142 & 0.169 \\
\hline Level of information sharing & -0.317 & 0.109 & -0.243 & -2.903 & $0.004^{\star *}$ & -0.533 & -0.101 \\
\hline Quality of Information Sharing & -0.197 & 0.107 & -0.154 & -1.838 & $0.0048^{\star *}$ & -0.409 & 0.015 \\
\hline
\end{tabular}

At 0.05 level of significance. 
Table 2. Correlation table.

\begin{tabular}{|c|c|c|c|c|}
\hline \multicolumn{5}{|c|}{ Correlations } \\
\hline & & $\begin{array}{c}\text { Supply Chain } \\
\text { Management } \\
\text { Practices }\end{array}$ & $\begin{array}{l}\text { Supply Chain } \\
\text { Practices }\end{array}$ & $\begin{array}{c}\text { SME } \\
\text { performance }\end{array}$ \\
\hline & Pearson Correlation & 1 & & 0.637 \\
\hline Supply Chain & Sig. (2-tailed) & 0.00 & 0.000 & 0.000 \\
\hline Management & $\mathrm{N}$ & 151 & 151 & 151 \\
\hline \multirow[t]{4}{*}{ Practices } & $\mathrm{R}$ & & & 86.2 \\
\hline & $\mathrm{F}$ & & & 234.71 \\
\hline & Pearson Correlation & & 1 & 0.856 \\
\hline & Sig. (2-tailed) & 0.000 & 0.000 & 0.000 \\
\hline \multirow{5}{*}{$\begin{array}{c}\text { Supply Chain } \\
\text { Practices }\end{array}$} & $\mathrm{N}$ & 151 & 151 & 151 \\
\hline & $\mathrm{R}$ & & & 40.6 \\
\hline & $\mathrm{F}$ & & & 666.8 \\
\hline & Pearson Correlation & & 0.854 & 1 \\
\hline & Sig. (2-tailed) & 0.000 & 0.000 & 0.000 \\
\hline \multirow[t]{3}{*}{ SME performance } & $\mathrm{N}$ & 151 & 151 & 151 \\
\hline & $\mathrm{R}$ & & 73.3 & \\
\hline & $\mathrm{F}$ & & 678.5 & \\
\hline
\end{tabular}

${ }^{* *}$ Correlation is significant at the 0.05 significant level (2-tailed).

\section{Discussion of Results}

\section{Relationship between Supply Chain Management Practices and Supply Chain Performance}

To test the relationship between SCM practices (SCMP) and supply chain performance (SCP) which was hypothesis 1. A linear regression was performed and Table 3 shows the relationship.

Table 4 shows that all the SCM practices are significantly and positively related to Firms' competitive advantage. An increase or improvement in SCMPs will improve the competitive advantage of the businesses. Therefore we fail to reject the null Hypothesis and conclude that there is a positive and significant relationship between SCMPs and Competitive Advantage.

Table 5 shows that all the competitive advantage variables were significantly and positively related to SMEs' performance. Therefore we fail to reject the null Hypothesis and conclude that there is a positive and significant relationship between Competitive Advantage and SMEs' performance. Hence, an increase in competitive advantage of the SMEs due to increase in SCMPs will consequently increase Business Performance. This is also referred to as the indirect route in 
Table 3. Hypothesis 1: Test for the relationship between SCMPs and SMEs performance.

\begin{tabular}{ccccc}
\hline Model & \multicolumn{2}{c}{$\begin{array}{c}\text { Unstandardized } \\
\text { Coefficients }\end{array}$} & $\begin{array}{c}\text { Standardized } \\
\text { coefficients }\end{array}$ & p-value \\
& B & Std. Error & Beta & sig \\
\hline (Constant) & 3.429 & 0.696 & & 0.000 \\
Strategic Supplier Relationship (SSR) & 0.401 & 0.100 & 0.308 & $0.000^{* *}$ \\
Customer Relationship & 0.013 & 0.079 & 0.013 & 0.864 \\
Level of information sharing & 0.317 & 0.109 & 0.243 & $0.004^{* *}$ \\
Quality of Information Sharing & 0.197 & 0.107 & -0.154 & $0.0048^{\star}$ \\
\hline
\end{tabular}

a. Dependent Variable: SMEs Financial Performance. Highlights indicates the variables which were significant in a multi-variable regression at 0.05 level of confidence. All the variables in SCM practices were significantly and positively related to financial performance of the SMEs except customer relations which was found to be insignificant. Therefore we fail to reject the null Hypothesis and conclude that there is a positive and significant relationship between SCMPs and SMEs performance.

Table 4. Hypothesis 2: Test for the relationship between SCMPs and competitive advantage.

\begin{tabular}{ccccc}
\hline Model & \multicolumn{2}{c}{$\begin{array}{c}\text { Unstandardized } \\
\text { Coefficients }\end{array}$} & $\begin{array}{c}\text { Standardized } \\
\text { coefficients }\end{array}$ & p-value \\
\hline & B & Std. Error & Beta & sig \\
\hline (Constant) & 3.088 & 1.793 & & 0.0000 \\
Strategic Supplier Relationship (SSR) & 0.046 & 0.216 & 0.044 & $0.0041^{* *}$ \\
Customer Relationship & 0.335 & 0.161 & 0.274 & $0.0005^{* *}$ \\
Level of information sharing & 0.297 & 0.320 & 0.145 & $0.00013^{* *}$ \\
Quality of Information Sharing & 0.517 & 0.174 & 0.541 & $0.0050^{* *}$ \\
\hline
\end{tabular}

a. Dependent Variable: Competitive Advantage (C1).

Table 5. Hypothesis 3: Test for the relationship between competitive advantage and SMEs performance.

\begin{tabular}{ccccc}
\hline Model & \multicolumn{2}{c}{$\begin{array}{c}\text { Unstandardized } \\
\text { Coefficients }\end{array}$} & $\begin{array}{c}\text { Standardized } \\
\text { coefficients }\end{array}$ & p-value \\
\hline B & Std. Error & Beta & sig \\
\hline (Constant) & 3.345 & 0.830 & & 0.000 \\
We offer competitive prices & 0.019 & 0.098 & 0.036 & $0.0021^{* *}$ \\
Able to compete base on quality & 0.099 & 0.131 & 0.130 & $0.0002^{* *}$ \\
we offer durable products & 0.864 & 0.287 & 0.825 & $0.0044^{* *}$ \\
we deliver the kind of products needed & 0.026 & 0.222 & 0.031 & $0.0009^{* *}$ \\
\hline
\end{tabular}

a. SMEs Financial Performance.

which SCMPs practices has an influence on Performance through Competitive advantage. 
The direct relationship between SCMPs and SMEs' performance indicates that SCMPs directly affect SME performance. This suggests that, within the context of SME performance, the adoption and successful implementation of SCMPs will directly improve their financial and market share performances in the long run. This effect is in line with comparable previous studies found in the literature (Shin, Collier, \& Wilson, 2000), which had not taken into consideration any intermediate variable(s) such as competitive advantage or SCP. The results show that there exists an immediate impact of SCP on SME performance. SME performance is also indirectly influenced by SCMPs through competitive Advantage.

Finally, the direct and indirect relationship between SCMPs and SMEs' performance indicates that SCMPs directly and indirectly affects SME performance. This suggests that well-managed and well-executed SCMPs in terms of flexibility and integration of the SCMPs, responding quickly to customers, and having a few highly dependable suppliers will directly have a positive effect on SME performance.

The influence of customer relationship on SMEs performance. The results are a bit mixed with regard to this variable. While literature indicates a significant positive correlation between the variable and Supply Chain Performance, the regression analysis does not support this relationship. It could be that customer relationship is not a significant factor overall in small and medium agro-dealers.

The influence of level of information sharing on SMEs' performance. The results show that level of information sharing positively affect Business performance either directly or indirect through competitive advantage $(p<0.005)$. Therefore, Hypothesis is supported. This means that any increase in the level of information sharing will increase business performance such as return on investment, growth in sales, etc.

The influence of quality of information sharing on SMEs' performance. The results showed that quality of information sharing positively affects Business performance either directly or indirect through competitive advantage $(p<$ 0.005). Therefore, hypothesis is supported. This means that any increase in Customer relationship management practices will increase the business performance.

The influence of strategic supplier relation on SMEs performance. The results showed that strategic supplier relation has a positive and significant relationship on business performance either directly or indirectly through competitive Advantage $(p<0.005)$. Therefore, hypothesis is supported. This means that any increase in strategic supplier relations practices will increase competitive advantage such as return on investment, growth in sales, etc.

Qualitative results

- Respondents who showed some knowledge of SCM did agree that ever since they started appreciating the SCM practices they have witnessed a rise in the 
quantity of sales they make in a year.

- However some agro-dealers especially those who operate on a very small operations did note that mostly they have no access to a lot of information about the supplied products as they mostly order them from wholesalers.

- They also indicated that mostly they fail to answer queries from customers as the information they have is sometimes not adequate to address the questions.

- Almost all the agro-dealers indicated that customers do not utilize the suggestion box even when it has been provided hence customer relations has been hard to achieve.

\section{Conclusion and Recommendations}

This study provides hard evidence indicating that higher levels of SCM practices can lead to enhanced supply chain and firms' performance. It also provides managers of agro-dealers with a multi-dimensional operational measure of the construct of SCMPs for assessing the comprehensiveness of the SCM practices of their firms. This study is among the very first SCM researches conducted on the SMEs particularly the agro-dealers, in relation to the practices that SMEs in this country need to adapt to make their supply chains a solid competitive vehicle for their development. The results have broader implications for all SMEs, particularly in developing economies where the growth of SMEs and the development of integrated supply chains are key stages in economic development. This paper provides empirical justification for a framework that identifies four key dimensions of SCM practices and describes the relationship among SCM practices, competitive advantage, and organizational performance. It examines three research questions: 1) do organizations with high levels of SCM practices have high levels of competitive advantage?; 2) do organizations with high level of SCM practices have high levels of organizational performance?; 3) do organizations with high levels of competitive advantage have a high level of organizational performance?

The research results show that although most agro-dealers use the supply chain when it comes to the implementation of the practices, these have not been well understood and implemented. SMEs and all organizations should accustom themselves to these practices as it is evident that they have direct impact on any organization performance in which a customer and a supplier are concerned. Further research should be carried out and look at business challenges associated with supply chain management.

\section{Conflicts of Interest}

The authors declare no conflicts of interest regarding the publication of this paper.

\section{References}

Balsmeier, P. W., \& Voisin, W. (1996). Supply Chain Management: A Time-Based Strat- 
egy. Industrial Management, 38, 24-27.

Childhouse, P., \& Towill, D. R. (2003). Simplified Material Flow Holds the Key to Supply Chain Integration. Omega, 31, 17-27. https://doi.org/10.1016/S0305-0483(02)00062-2

Chizzo, S. A. (1998). Supply Chain Strategies: Solutions for the Customer-Driven Enterprise. Software Magazine, Supply Chain Management Directions Supplement, 4-9 January, 1998.

Clark, T. H., \& Lee, H. G. (2000). Performance, Interdependence and Coordination in Business-to-Business Electronic Commerce and Supply Chain Management. Information Technology and Management, 1, 85-105. https://doi.org/10.1023/A:1019108621684

Donlon, J. P. (1996). Maximizing Value in the Supply Chain. Chief Executive, 117, 54-63.

Gunasekaran, A., Patel, C., \& Tirtiroglu, E. (2001). Performance Measures and Metrics in a Supply Chain Environment. International Journal of Operations and Production Management, 21, 71-87. https://doi.org/10.1108/01443570110358468

Li, S., Rao, S., Ragu-Nathan, T. S., \& Ragu-Nathan, B. (2002). An Empirical Investigation of Supply Chain Management Practices. In Proceedings of the 33rd Annual Meeting of the Decision Science Institute.

Magretta, J. (1998). The Power of Virtual Integration: An Interview with Dell Computers' Michael Dell. Harvard Business Review, 76, 72-84.

McGinnis, M. A., \& Vallopra, R. M. (1999). Purchasing and Supplier Involvement in Process Improvement: A Source of Competitive Advantage. Journal of Supply Chain Management, 35, 42-50. https://doi.org/10.1111/j.1745-493X.1999.tb00243.x

Shin, H., Collier, D. A., \& Wilson, D. D. (2000). Supply Management Orientation and Supplier/Buyer Performance. Journal of Operations Management, 18, 317-333. https://doi.org/10.1016/S0272-6963(99)00031-5

Stern, L., \& Reve, T. (1980). Distribution Channels as Political Economies: A Framework for Competitive Analysis. Journal of Marketing, 44, 52-64. https://doi.org/10.1177/002224298004400306

Stuart, F. I. (1997). Supply-Chain Strategy: Organizational Influence through Supplier Alliances. British Academy of Management, 8, 223-236. https://doi.org/10.1111/1467-8551.00062

Tan, K. C., Lyman, S. B., \& Wisner, J. D. (2002). Supply Chain Management: A Strategic Perspective. International Journal of Operations and Production Management, 22, 614-631. https://doi.org/10.1108/01443570210427659

Wong, C. Y., Arlbjorn, J. S., \& Johansen, J. (2005). Supply Chain Management Practices in Toy Supply Chain. Supply Chain Management: An International Journal, 10, 367-378. https://doi.org/10.1108/13598540510624197

Yoshino, M., \& Rangan, S. (1995). Strategic Alliances: An Entrepreneurial Approach to Globalization. Harvard Business School Press. 